\title{
The provision of unpaid care across cohorts and genders: A Research Note
}

\author{
Christine Proulx ${ }^{1}$
}

\begin{abstract}
In this study, the caregiving history collected in the 2007 General Social Survey (GSS) is used to document the provision of care since the age of 15 years, the number of people helped, and the relationship with the care recipients. Using life tables, we confirm an upward trend in caregiving across birth cohorts. Unexpectedly, the findings also show that providing care starts at earlier ages in more recent cohorts- a result that appears partly linked to the emergence of new care relationships-and that the gender gap in the provision of care has widened over time.
\end{abstract}

Keywords: Canada; caregiving; gender; cohorts; life tables.

\section{Résumé}

Dans le cadre de cette étude, nous examinons les soins fournis depuis l'âge de 15 ans, le nombre de personnes aidées et la nature des liens avec ces personnes en nous basant sur l'historique des soins prodigués recueilli dans l'Enquête sociale générale (ESG) de 2007. À l'aide de tables d'extinction simple, nous confirmons l'augmentation de la prestation de soins au fil des cohortes de naissance. Par ailleurs, les soins commencent de plus en plus tôt, notamment grâce à l'apparition de nouveaux types de relations d'aide, et l'écart dans la prestation de soins se creuse entre les hommes et les femmes.

Mots-clés : Canada; prestation de soins; genre; cohortes; tables d'extinction simple.

\section{Introduction}

In 2012, 8.1 million Canadians representing 28 per cent of the population aged 15 years and over and living in the community reported providing some type of care to relatives or friends (Sinha 2013). Age-related needs of the care recipient were by far the reason most frequently cited for the assistance provided by individuals. With the aging of the population, the need for care is expected to increase in the future. In 2036, one in four Canadians will be aged 65 years or older, a marked increase from their 16 per cent share of the population in 2014 (Statistics Canada 2010, 2014a). The proportion of the population aged 75 years and older will increase from 8 per cent in 2014 to 13 per cent in 2036. A large majority of care recipients receive help from family members, relatives, or friends who are not paid for the care they provide (Sinha and Bleakney 2014). Considering the greater care needs at older ages and government policies prioritizing aging in the community and care in the home (Keefe et al. 2005; Lavoie 2012), the reliance on unpaid caregivers is unlikely to fade in years to come.

Our understanding of how common the provision of unpaid care is in Canada as well as how it has evolved over time is limited due to the absence of data collected prior to 1996. The number of caregivers appears to have increased over the past two decades. Is the increase linked to a similar increase across cohorts of the proportion of those who provide care or is it also related to a change in tempo, that is, the age at which individuals start providing care? The analysis of individuals' care histories, which can be approached with retrospective survey data, can shed light on the life stage at which care responsibilities arise which is informative of the responsibilities generally associated with that life stage and of the potential consequences that providing care might have regarding other domains of their life, such as the caregiver's health, employment and family life. The

1. Research carried out while completing doctoral studies at McGill University. Email: cproulx05@gmail.com. 
Proulx: The provision of unpaid care across cohorts and genders

repercussions of caregiving in the lives of individuals may vary depending upon the timing over the life course (Elder 1998). This no doubt constitutes valuable information for policymakers who may develop services to the population according to caregivers' needs at different stages of their lives. In addition, gaining a better understanding of past trends in caregiving by observing the experiences of successive birth cohorts could shed light on whether these trends will be maintained or not.

The 2007 General Social Survey (GSS) constitutes the very first attempt in Canada at gathering the complete caregiving history of individuals. The survey provided information collected about a total of five care episodes experienced by respondents since the age of 15, elaborating as well on whether or not they had provided care in the twelve months prior. The reconstruction of the respondents' care history allows us to estimate the percentage of individuals who have provided care at least once in their life, the age at which they started doing so and the extent to which these have changed across cohorts. In addition, this paper examines differences in the cumulated probabilities of men and women to provide care and their variations across birth cohorts. A convergence across cohorts in the proportions of men and women who provide care at least once over the course of their lives would support expectations of an increasing similarity in gender roles over time. However, a divergence would challenge our ideas about the evolution of gender roles and motivate a search for alternative explanations.

\section{Literature review}

\section{The increasing proportion of caregivers in the Canadian population}

Statistics Canada collected information on caregiving for the first time as part of the 1996 GSS (Statistics Canada 2013). Cycles on social support were repeated in 2002, 2007 and 2012, but changes in the population surveyed and definitions of care make it difficult to readily compare published estimates. With these limitations in mind, a close look at the proportions of caregivers in each of these years suggests that they have been increasing over the past 20 years. Table 1 presents a summary of these estimates.

In 1996, 12,756 Canadians aged 15 years and over and living in private households in one of the ten provinces were asked whether they had provided care to persons with a long-term health condition or physical limitation in the year preceding the survey. The population of caregivers was estimated at 2.85 million, of which nearly half were less than 45 years old (Fast et al. 2011; Fast and Keating 2001). According to this survey, 10 and 14 per cent of Canadian men and women aged 15 and over, respectively, had been providing care to at least one person during the year prior to the survey (Cranswick 1997). A large share of caregivers provided care to a senior. In all, 2.1 million Canadians, representing 11 per cent of the population aged 15 years and over, helped at least one person over the age of 65 (Fast and Keating 2001).

In 2002, the target population was restricted to individuals aged 45 years and over and caregiving questions concerned only assistance provided to seniors. According to this survey, 2 million Canadians aged 45 years and over-19 per cent of men and 18 per cent of women — had provided eldercare for a long-term health problem within the year prior to the survey, an increase from the approximate number of 1 million people of that age group estimated in the 1996 GSS (Cranswick and Dosman 2008).

The range of information collected on caregiving was far more extensive in the 2007 GSS. A wide array of questions were asked of respondents aged 45 and over about the care for a long-term health condition or physical limitation provided in the twelve months preceding the survey. Further questions were also asked about the episodes of care that respondents provided to up to five persons since the age of 15 . Studies using this dataset suggested that 3.8 million—or 29 per cent of the Canadian population aged 45 and over-had provided care in the year prior to the 2007 GSS, among whom 2.7 million, 19 per cent of men and 22 per cent of women, provided care to a senior (Cranswick and Dosman 2008; Fast et al. 2011). These studies thus suggest that the number of people 45 years and over who provide care to seniors increased by approximately 700,000 between 2002 and 2007 and that the increase was due primarily to the addition of women, the proportion of female caregivers rising from 18 to 22 per cent between the two surveys. The focus on the assistance provided in a given year does not give a good indication of how common the provision of care can be over one's life course. Indeed, 
Table 1. Estimates of the proportion of caregivers in the population published using data from the 1996, 2002, 2007, and 2012 General Social Surveys (GSS)

\begin{tabular}{|c|c|c|c|c|}
\hline & 1996 & 2002 & 2007 & 2012 \\
\hline $\begin{array}{l}\text { \% provided } \\
\text { care in past } 12 \\
\text { months }\end{array}$ & $\begin{array}{l}10 \% \text { of men } \\
14 \% \text { of women } \\
\text { (Cranswick 1997) }\end{array}$ & - & $\begin{array}{l}29 \% \\
\text { (Fast et al. 2011) }\end{array}$ & $\begin{array}{l}28 \% \\
\text { (Sinha 2013) }\end{array}$ \\
\hline $\begin{array}{l}\% \text { provided care } \\
\text { since age } 15\end{array}$ & - & - & $\begin{array}{l}40 \% \text { of men } \\
52 \% \text { of women } \\
\text { (Fast et al. 2013) }\end{array}$ & $\begin{array}{l}46 \% \\
\text { (Sinha 2013) }\end{array}$ \\
\hline $\begin{array}{l}\% \text { provided } \\
\text { eldercare in past } \\
12 \text { months }\end{array}$ & $\begin{array}{l}11 \% \\
\text { (Fast and Keating } \\
\quad 2001)\end{array}$ & $\begin{array}{l}19 \% \text { of men } \\
18 \% \text { of women } \\
\text { (Cranswick and Dosman } \\
\text { 2008) }\end{array}$ & $\begin{array}{l}19 \% \text { of men } \\
22 \% \text { of women } \\
\text { (Cranswick and Dosman } \\
\text { 2008) }\end{array}$ & - \\
\hline $\begin{array}{l}\text { Age restriction } \\
\text { of sample }\end{array}$ & $15+$ & $45+$ & $45+$ & $15+$ \\
\hline $\begin{array}{l}\text { Definitions of } \\
\text { care }\end{array}$ & $\begin{array}{l}\text { Assisted someone } \\
\text { with child care, } \\
\text { meal preparation } \\
\text { and clean-up, } \\
\text { house cleaning, } \\
\text { laundry, sewing, } \\
\text { house maintenance, } \\
\text { outdoor work, } \\
\text { shopping for } \\
\text { groceries and } \\
\text { other necessities, } \\
\text { transportation } \\
\text { or personal care } \\
\text { because of a } \\
\text { long-term health } \\
\text { condition or physical } \\
\text { limitation in the past } \\
12 \text { months }\end{array}$ & $\begin{array}{l}\text { Assisted someone over } \\
\text { the age of } 65 \text { with meal } \\
\text { preparation and clean- } \\
\text { up, house cleaning, } \\
\text { laundry, sewing, } \\
\text { house maintenance, } \\
\text { outdoor work, shopping } \\
\text { for groceries and } \\
\text { other necessities, } \\
\text { transportation or } \\
\text { personal care because } \\
\text { of a long-term health } \\
\text { condition or physical } \\
\text { limitation in the past } \\
12 \text { months (child care } \\
\text { assistance only asked to } \\
\text { respondents } 65 \text { years and } \\
\text { older) }\end{array}$ & $\begin{array}{l}\text { Assisted someone with } \\
\text { meal preparation and } \\
\text { clean-up, house cleaning, } \\
\text { laundry, sewing, } \\
\text { house maintenance, } \\
\text { outdoor work, shopping } \\
\text { for groceries and } \\
\text { other necessities, } \\
\text { transportation, personal } \\
\text { care, coordination } \\
\text { of caregiving tasks, } \\
\text { medical treatments } \\
\text { or managing finances } \\
\text { because of a long-term } \\
\text { health condition or } \\
\text { physical limitation in the } \\
\text { past } 12 \text { months } \\
\text { AND } \\
\text { Assisted someone since } \\
\text { age } 15 \text { (up to } 5 \text { care } \\
\text { recipients listed) }\end{array}$ & $\begin{array}{l}\text { Assisted someone with } \\
\text { meal preparation and } \\
\text { clean-up, house cleaning, } \\
\text { laundry, sewing, } \\
\text { house maintenance, } \\
\text { outdoor work, shopping } \\
\text { for groceries and } \\
\text { other necessities, } \\
\text { transportation, personal } \\
\text { care, coordination of } \\
\text { caregiving tasks, medical } \\
\text { treatments or managing } \\
\text { finances because of } \\
\text { a long-term health } \\
\text { condition, physical } \\
\text { limitation or aging needs } \\
\text { in the past } 12 \text { months } \\
\text { AND } \\
\text { Assisted someone since } \\
\text { age } 15 \text { (up to } 5 \text { care } \\
\text { recipients listed) }\end{array}$ \\
\hline
\end{tabular}

more than half of women (52 per cent) and 40 per cent of men 45 years and over provided care at least once at some point in their lives since the age of 15 , a much higher proportion than 29 per cent characterizing those who assisted someone in the previous year (Fast et al. 2013).

In 2012, the most recent cycle of the GSS to focus on caregiving and care-receiving, 28 per cent of individuals aged 15 years and over provided care, a sharp increase from the percentage of 10-14\% derived from the 1996 GSS (Cranswick 1997; Sinha 2013). Expanding the definition of care to include aging needs in addition to long-term health conditions or disabilities probably accounts for part of the increase observed but surely cannot explain its entirety. Again, a number of individuals (46 per cent) had provided care at some point during their lives (Sinha 2013). Caregiving appears to be on the rise and the increase described above took place over a relatively short period of time.

Whether this trend was already ongoing prior to the 1990s remains unclear since, to our knowledge, no Canadian study used the retrospective information on caregiving available in the last two cycles of the GSS on social support to examine the prevalence of care across cohorts. Using this information would increase the period over which caregiving could be studied to the latter half of the 20th century and beginning of the 21 st century. A closer look at past trends in caregiving may help us understand where trends may head in the future. The next few paragraphs review other studies' findings regarding the evolution of caregiving across cohorts and provide reasons to expect similar developments in Canada. 
Proulx: The provision of unpaid care across cohorts and genders

\section{Changes in proportions of caregivers across birth cohorts}

One U.S. study of married women living in a mid-sized community in upstate New York used such retrospective information about the care provided over the life course (Robison et al. 1995). Four birth cohorts were compared and an increase in the proportions of women who provided care to someone of an older generation, a person of the same generation or a person of a younger generation was witnessed across cohorts. For example, 17 per cent of women born between 1905 and 1917 had provided care to an older person who was sick or infirm at some point in their lives compared to 33 per cent of women born between 1927 and 1934.

Another study, using a quasi-cohort approach with four cycles (1985, 1990, 1995 and 2000) of the British General Household Survey (GHS), also found that mid-life men and women increasingly took on caregiving responsibilities for a sick, disabled or elderly person across birth cohorts (Evandrou and Glaser 2002). Between the ages of 55 to 59 years old, 19 per cent of women and 12 per cent of men born between 1926 and 1930 reported providing some type of care compared to 28 and 20 per cent, respectively, in the 1941-45 cohort. These substantially lower proportions than in the U.S. study described above can be attributed to the cross-sectional nature of the GHS.

A number of reasons lead us to believe that an increase in caregiving over the life course could also be witnessed across cohorts in Canada. Firstly, the de-institutionalization of the elderly and of other persons with disabilities that took place in the 1980s shifted more of the responsibility for care to family members (Lavoie 2012). Home care services were implemented during the 1980s to help seniors remain in their home but the resources for those services remained limited compared to the services provided in institutions in the 1960s and 1970s (Lavoie 2012; Protecteur 2012) These institutional changes likely increased the proportion of individuals who had to provide care without pay.

Secondly, given the steady increase in life expectancy over the past 90 years (Decady and Greenberg 2014), it has become increasingly common for multiple generations of a family to be able to maintain relationships over several years. In a seminal lecture, Bengtson (2001: 12) used the expression "longer years of shared lives" to describe this phenomenon, which he asserts is likely to yield new forms of interactions. We would argue that the increasing involvement of younger generations in relations of care may be such a form of interaction. Providing care to a grandparent might have been a rare event for the parents of the baby boomers, who were less likely than their children and grandchildren to have known their grandparents. These relationships, although not as frequent as other care relationships such as the aging parent-adult child dyad, are becoming more common. For example, in 2000 it was estimated that grandchildren accounted for 8 per cent of caregivers in the United States (Foundation 2003, as cited in Fruhauf et al. 2006). Young adults and children sometimes act as an additional source of care to that provided by their parents, and they may find in this activity a way to return to their grandparents the support they received from them earlier in their lives (Fruhauf et al. 2006; Szinovacz 2008). It is unknown whether the provision of care by grandchildren displaces the assistance provided by other members of the family, or rather adds to the latter, thus increasing the size of the care network of elderly persons. The latter is plausible, since many grandchildren caregivers appear to act as secondary sources of support (Fruhauf et al. 2006).

Third, new forms of care relationships may have emerged as a result of the increasing conjugal instability observed since the late 1960s (Ménard and Le Bourdais 2012). While it was relatively common in the past for individuals to rely on a spouse or partner when in need of assistance, turning to friends for support may be increasingly common, especially following separation or divorce. The data published until now does not support an increase in friend caregiving. Sixteen percent of unpaid caregivers provided care to a friend, colleague or neighbour in 2012 compared to 24 and 13 per cent for instrumental and personal care, respectively, in 1996 (Cranswick 1997; Sinha 2013). In 2012, only 8 per cent helped a partner (Sinha 2013). However, it is two different things to compare proportions of caregivers who helped a friend and to scrutinize proportions of the population who were friend caregivers. It is possible that the relative share of non-kin caregivers decreased because the number of parent caregivers, for example, substantially increased, but that their share in the general population (including individuals not providing care) still increased. Friend caregivers report spending on 
average fewer hours per week providing care than spouses and partners or other close relatives (Himes and Reidy 2000; Sinha 2013). However, research has shown that the number of hours of assistance received is not affected by the proportion of kin versus non-kin in the family/friend care network (Fast et al. 2004). Perhaps, non-kin networks are larger in size than kin-only networks, which would explain why care recipients do not differ in the amount of care received depending upon the relationship composition of their network and why a decrease in partner caregiving could be accompanied by an increasing involvement of others than partners, including friends.

Lastly, the proportion of caregivers reported in surveys might have increased in part due to a change in perceptions about the caregiver role. Guberman et al. (2011) suggest that baby boomers consider their caring responsibilities as a role in itself, a shift from the perspective of their parent generation who perceived these as an aspect of their natural roles of mother, daughter, or wife. Furthermore, baby boomer caregiving women voice the importance to maintain their other activities, paid work and social activities, and not having to sacrifice those to take on caregiving, although, in practice, many do make a considerable amount of changes in their professional and personal lives as a consequence of caregiving. They tend to find the use of formal services as acceptable, services they believed were not available to their mothers who had no choice but to provide care to other family members. Because of their perception of caregiving as a role in itself, it is thus reasonable to expect that baby boomers will be more likely to report periods of caregiving than previous generations.

\section{Gender differences in caregiving}

Women have traditionally engaged in caring work and housework and they continue to form the majority of caregivers (Cranswick and Dosman 2008; Fast et al. 2011; Sinha 2013). Women also spend on average more hours per week in that role and are more involved in the provision of personal care and housework than are men, tasks that need to be done on a regular schedule. Only in one domain, that of household maintenance and outdoor work do men invest more time than women. Nonetheless, in 2012, men accounted for 46 per cent of all caregivers aged 15 and over (Sinha 2013). This proportion is substantial and probably higher than it used to be 50 or 60 years ago, when gender roles were more segregated. Yet, caregiving still characterizes the lives of greater proportions of women than of men. Indeed, 52 per cent of women and 40 per cent of men 45 years and over in 2007 had provided care at least once since age 15 (Fast et al. 2013).

A study on the provision of care over the life course conducted with British data suggested that women start assuming caregiving responsibilities for a first time at a faster rate than men almost throughout their lives (Henz, 2004). The hazard rate of first caring increases steadily from the ages of 15 to 40, but men's rate is consistently half that of women. Then, the rate of women peaks at age 50 when 23 women per 1000 who had not yet provided care enter that role. After that age, women's rate falls, even briefly below men's, which remains steady at 10 per 1000 between the ages of 54 and 65. However, hazard rates present another side of the story than cumulative probabilities over time. Although women's hazard rates are below men's during two years at ages 63 and 64, the proportion of women who provided care at least once is surely greater than men's since they have been entering first care at a higher rate throughout their life before that age.

Apart from gender role explanations, there does not seem to be many theories on why women would be more involved in caregiving than men. A qualitative study of siblings whose parents were at least 75 years old suggests that brothers and sisters have different approaches in how they interact with their parents, differences which may become more pronounced as parents' needs increase (Matthews 2002). On the one hand, brothers tend to wait for their parents' requests for help as they want to encourage them to be self-reliant. On the other hand, sisters are generally proactive and offer assistance regularly without waiting for their parents requests for help. In families where there are brothers and sisters, brothers generally provide more assistance than in only-sons or brothers-only families, possibly because their sisters who hold a familial view of responsibility pressure them into doing so. Despite their implication, sisters tend to perceive their brother's contribution as not sufficient. 


\section{Converging gender roles and norms}

Although men and women may differ in their approaches to care, with women more often involved in tasks that need to be done on a regular basis, the gender differences in the proportion of caregivers in the population could be less pronounced today than in the past. With the profound transformations in gender roles and norms observed over the past few decades, proportions of men and women who engage in family or friend caregiving could be converging. Although estimates are difficult to compare, there is some evidence of a convergence between 2007 and 2012. In 2007, 43.5 per cent of caregivers aged 45 and over were men compared to 46 per cent of those 15 years and over in 2012 (Fast et al. 2011; Sinha 2013). This convergence is likely to originate from a relatively greater increase in the number of men involved in caregiving than in that of women.

One of the major components of the observed social transformation in gender roles is the greater participation of women in the sphere of paid employment, which has increased dramatically, from below 40 per cent in the 1960s to 62 per cent in 2013 (Engelhardt and Prskawetz 2004; Statistics Canada 2014b). It is now common for both members of a couple to engage in paid employment (Marshall 2006). However, the narrowing of the gender gap in unpaid labour has occurred much less rapidly than in paid work. Hochschild and Machung (1997) described how women engaged in paid work dealt with a second shift of housework and childcare once they returned home. Whereas a gap of one hour per day still exists between men and women in the amount of time spent doing unpaid work in the home, time-use surveys show that,between 1986 and 2005, men aged 25 to 54 increased their number of hours, while their female counterparts saw theirs diminished (Marshall 2006). Arrangements in the division of paid and unpaid work among couples have become more diversified, with the traditional model losing ground and couples sharing roles becoming more common (Ravanera et al. 2009). The gender differences noted in unpaid work, and the observed evolution in gender roles and norms, motivate us to conduct a separate analysis for men and women, in order to assess the extent of changes across cohorts in the provision of caregiving over a life course.

\section{Research questions}

The objective of this study is to examine the population of men and women who have experienced caregiving over the course of their lives. More specifically, we aim to estimate (1) the proportion of individuals who have provided care at least once since age 15; (2) the number of people to whom they have provided care; and (3) the nature of the relationship with the persons whom they have helped. We expect the proportion of individuals who have been caregivers at least once in their lives to be higher than the 29 per cent observed by Fast et al. (2011) for the year 2007, and closer to 40 and 52 per cent, the respective proportions of men and women aged 45 and over who had provided care to a family member or a friend at some point in their lives (Fast el al. 2013).

Using the life table method to estimate the cumulated probabilities of men and women to experience a first care episode across four birth cohorts, we examine (4) whether or not providing care has become more common among more recent cohorts; and (5) whether or not the timing of the first care episode has changed across cohorts. Our separate analysis by gender seeks to estimate (6) whether or not the gap in the experience of caregiving separating men and women has narrowed over time. Finally, we aim to (7) observe any possible emergence among later cohorts of such new care relationships as care to grandparents and to friends.

\section{Data and method}

\section{Data}

The General Social Survey (GSS) is an annual survey conducted by Statistics Canada and is representative of the Canadian population living in private households in the ten provinces. We use cycle 21 collected in 2007 because it was the first GSS to collect retrospective information about the experience of caregiving. It constitutes 
the best opportunity to go further back in time to study changing trends in caregiving. The 2007 GSS collected information on family, social support and retirement from a sample of 23,404 respondents aged 45 years and over who were interviewed by phone. Two modules assessed the provision of unpaid care to family members, relatives and friends.

Participants were first asked if they had provided assistance to a person because of a long-term health condition or physical limitation in the twelve months prior to the survey. If they reported giving help for at least one care task - transportation, shopping, banking and bill paying, meal preparation and housework, house maintenance and outdoor work, personal care, medical care, coordination of caregiving tasks and management of finances - they were then asked to report the number of persons to whom they provided assistance. They also had to respond to a series of questions regarding the main care recipient. These included the latter's age and gender, the relationship respondents had with this person, the date at which they started providing care, the frequency with which assistance was provided for each task, the residential proximity and the type of dwelling of the care recipient.

In a further section of the survey, respondents were asked to indicate the number of people they had helped for a period of six months or longer, excluding those helped in the past twelve months, since the age of 15 . The start and end dates of up to five care episodes were collected, along with the relationship to each care recipient. Besides the date at onset of the episode of care, only relationship to each care recipient was collected in both modules. In order to determine which care episode came first in the lives of respondents to examine the timing of the first caregiving episode, we had to merge the two modules: the episode with the primary care recipient that occurred in the previous twelve months and all the other episodes that occurred since the age of 15 . In order to exclude the episodes recorded in the previous year of the survey that lasted less than six months, we retained only those starting in 2006 or earlier. Respondents' complete caregiving histories could thus contain up to a maximum of six caregiving episodes that lasted at least six months.

\section{Sample}

The sample of the present study includes individuals who never provided care and those who did at least once over the course of their lives. In order to establish the timing of the first caregiving episode among caregivers, we needed their complete history of caregiving. Missing dates for even one caregiving episode prevented us from ordering all episodes and consequently from studying the timing of first care. Of the original sample of 23,404 respondents, we excluded 1,011 individuals who were not sure whether or not they had helped anyone. The caregiving history was de facto incomplete for another 2,299 participants who had provided care to more than one person in the twelve months preceding the survey but for whom only the information on the care provided to the main care recipient was collected by Statistics Canada. Finally, 1,063 respondents were excluded because of missing information on start/end dates or relationships for some care episodes or because they had provided care to more than five persons since the age of 15 . The start date of the sixth and subsequent episodes were thus missing and we could not ascertain that these episodes followed chronologically the first five episodes. The analytic sample thus contains 19,031 respondents, some of whom provided care over the course of their lives and others who did not.

Because the large majority of excluded cases reported having provided care at least once in their life but had missing information in their caregiving history, the proportions of lifetime caregivers that we estimated are conservative. A detailed analysis showed that women are slightly overrepresented among the excluded cases, which is not surprising given their greater propensity to provide care relative to men. The way the survey was designed made it impossible for the large number of respondents who helped more than one person in the year preceding the survey to report the start date and their relationship with all those they helped. In fact, they were only asked the date at which they started providing care to their main care recipient, but not for the others they helped during that year. The exclusion of these cases is thus not due to a recall bias. If it had been, we should have found a greater proportion of older than younger individuals excluded from the sample, which is clearly not the case here. 


\section{Method}

We use life tables to estimate the cumulated probability, by age of respondent, of experiencing the onset of a first caregiving episode. The youngest age at which individuals could experience this transition was fixed at 15 years by Statistics Canada. ${ }^{2}$ In the life table method, subjects are considered at risk of experiencing a transition, that is, of becoming a caregiver, until they experience that transition or until they are no longer under observation, in which case they become censored (i.e., retrieved from the risk group). In other words, respondents who never had provided unpaid care contributed to the calculation of the cumulated probabilities of providing care from age 15 until the time of the survey in 2007. Hence, all respondents are observed until at least age 45 .

The cumulated probabilities of providing care for the first time were estimated separately for men and women among four birth cohorts. All but the earliest birth cohort span ten years. The earliest cohort, born prior to 1933, includes respondents who were aged 75 years and over at the time of survey in 2007; the other three cohorts were born between 1933 and 1942 (aged 65-74 years), 1943 and 1952 (aged 55-64 years), and 1953 and 1962 (aged 45-54 years).

Frequency tables are used to provide, separately for men and women, the distribution of respondents' birth cohort, number of care recipients since age 15, and relationship with care recipients. Another table presents, separately by cohorts, the respondents' relationship with their first care recipient for care episodes starting before age 45. Population weights are applied to percentages and cumulated probabilities.

\section{Results}

Table 2 presents some characteristics of the 8,250 men and 10,781 women aged 45 years and older in 2007 whose data was retained for the analysis. Given their greater life expectancy, it is not surprising to find that a larger percentage of women than men were born prior to 1933. In contrast, a larger share of men than women belongs to the Baby Boom cohorts of 1943-52 and 1953-62.

Caregiving is a common experience. Table 2 shows that 38.7 per cent of them provided care at least once for a period of six months or longer since the age of 15 . Women were more likely to engage in the provision of care compared to their male counterparts, and to provide care to a larger number of recipients over the course of their lives. Twenty-eight percent of women provided care to one person, 11 per cent helped two persons, and 6 per cent assisted at least three persons. Although lower, the men's contribution should not be understated, with 22 per cent who helped one person, 8 per cent who assisted two persons, and 3 per cent who provided care to three or more persons since they were 15 years old.

Consistent with the literature, helping a mother was the most frequent care relationship observed, with 13 per cent of men and nearly 24 per cent of women ever providing care to their mother. More than one in ten women provided assistance to another relative or to their father, compared to 8 per cent of men. Providing care to a spouse or partner appears to be less common. Nearly 5 per cent of men and 7 per cent of their female vis-àvis helped their ill or disabled partner at some point in their lives, percentages that are similar to those observed for the provision of care to a non-relative.

The experience of caregiving is common, and it has become even more common over time, as can be seen in Figure 1, which depicts the cumulated probabilities of men and women who provided care for the first time by birth cohort. Cohorts differ significantly in their experience of caregiving. The earliest cohort (represented by a dash-dot line) exhibits the lowest probability of providing care at any age throughout the life course, and the progression of experiencing caregiving is constant across cohorts. Hence, the cohort representing those born between 1953 and 1962 (solid line) presents the highest cumulated probability of having ever provided care at any age up until age 54 years (the maximum age of this cohort at survey). For instance, at age 40 years,

2. Even if the question asked respondents to report only those episodes that occurred since age 15 , a very small number of respondents reported care episodes starting earlier. These episodes were not considered in the analysis, but the respondents remained in the analysis. 
6 per cent of men born prior to 1933 had provided care for the first time compared to 17 per cent of those born between 1953 and 1962. A greater proportion of women had already been caregivers at that age, with one woman in ten from the earliest cohort and 23 per cent of those from the latest cohort having done so. In other words, the percentage of respondents who had ever provided care by age 40 years more than doubled, from the earliest to the latest cohorts of women, and nearly tripled among the cohorts of men.

Table 2. Characteristics of Canadian men and women aged 45 years and over in 2007

\begin{tabular}{|c|c|c|c|}
\hline & Men & Women & Total \\
\hline \multicolumn{4}{|l|}{ Birth cohort*** } \\
\hline Born prior to 1933 & 13.1 & 16.8 & 15.0 \\
\hline $1933-42$ & 17.3 & 18.5 & 17.9 \\
\hline $1943-52$ & 30.2 & 28.4 & 29.3 \\
\hline $1953-62$ & 39.4 & 36.4 & 37.8 \\
\hline \multicolumn{4}{|c|}{ Number of care recipients since age $15^{* * *}$} \\
\hline 0 & 67.8 & 55.2 & 61.3 \\
\hline 1 & 21.6 & 28.0 & 24.9 \\
\hline 2 & 7.6 & 10.8 & 9.3 \\
\hline 3 or more & 3.0 & 6.0 & 4.5 \\
\hline \multicolumn{4}{|c|}{$\begin{array}{l}\text { Ever provided care to... } \\
\text { A spouse/partner*** }\end{array}$} \\
\hline No & 95.3 & 92.9 & 94.1 \\
\hline Yes & 4.7 & 7.1 & 5.9 \\
\hline \multicolumn{4}{|l|}{ A mother*** } \\
\hline No & 87.4 & 76.5 & 81.8 \\
\hline Yes & 12.6 & 23.5 & 18.2 \\
\hline \multicolumn{4}{|l|}{ A father*** } \\
\hline No & 91.9 & 89.2 & 90.5 \\
\hline Yes & 8.1 & 10.8 & 9.5 \\
\hline \multicolumn{4}{|l|}{ A parent-in-law } \\
\hline No & 95.4 & 95.4 & 95.4 \\
\hline Yes & 4.6 & 4.6 & 4.6 \\
\hline \multicolumn{4}{|l|}{ Another relative*** } \\
\hline No & 92.3 & 88.1 & 90.1 \\
\hline Yes & 7.7 & 11.9 & 9.9 \\
\hline \multicolumn{4}{|l|}{ A non-relative*** } \\
\hline No & 94.4 & 92.9 & 93.6 \\
\hline Yes & 5.6 & 7.1 & 6.4 \\
\hline $\mathrm{N}$ (unweighted) & 8,250 & 10,781 & 19,031 \\
\hline \multicolumn{4}{|c|}{$\begin{array}{l}\text { Note: Chi-square tests significance levels: } \dagger p<.10 ;{ }^{*} p<.05 ; * * \\
p<.01 ; * * * p<.001 \text {. Some percentages do not add up to } 100 \text { due to } \\
\text { rounding. The percentages are based on population weight data. }\end{array}$} \\
\hline Source: General Socic & & & \\
\hline
\end{tabular}

The proportion of respondents who will have ever provided care by the end of their life is increasing across cohorts. Whereas the highest proportion (nearly 35 per cent) of men from the earliest cohort who reported having ever provided care was reached around age 85 years, a higher fraction of men had already done so at younger ages in the more recent cohorts. For example, 43 per cent of the men born in 1943-52 had experienced caregiving by age 64 years (the maximum age in this cohort), and this percentage is likely to keep increasing as they get older. A similar pattern can be observed among women. Slightly over 40 per cent of the earliest cohort of women reported ever providing care to someone; nearly 60 per cent of them had done so by age 64 years in the 1943-52 cohort. 

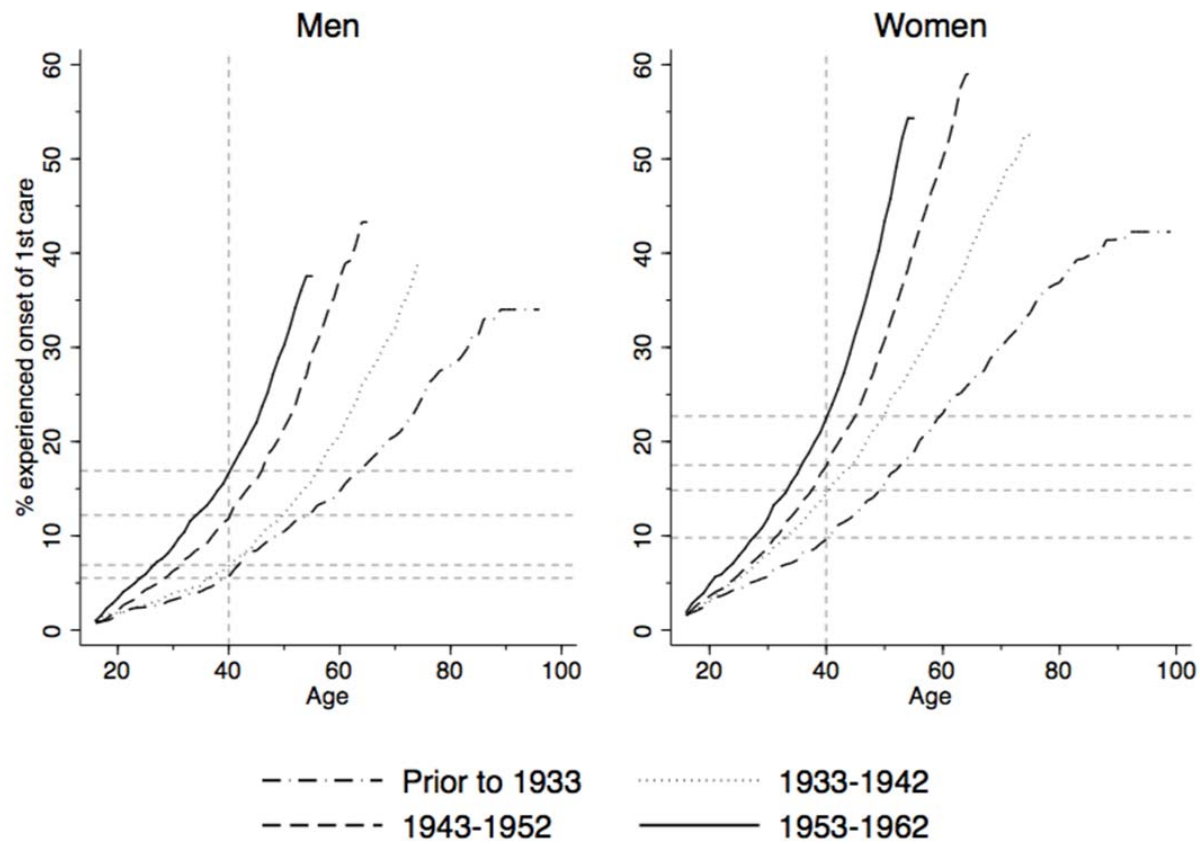

Figure 1. Cumulated probabilities of starting to provide care for the first time according to sex and birth cohort.

Source: General Social Survey 21. The cumulated probabilities are based on population weight data.

The differences observed between men and women in the proportions who ever provided care remain significant across all cohorts. Women are more likely than men to provide care over their life course. This pattern becomes obvious when comparing the horizontal lines denoting the proportions of individuals who had provided care by age 40 . No signs of a narrowing gap between genders are found across cohorts. The gap between men's and women's proportions of first caregiving by age 40 passes from 4 percentage points in the earliest cohort to 6 percentage points in the latest cohort, a 50 per cent increase. In fact, the gap at the time of survey between men and women appears to be increasing even more, from 8 percentage points among the cohort born prior to 1933 to 14 percentage points in the 1933-42 cohort, 16 percentage points in the 1943-52 cohort and finally 17 percentage points in the latest (1953-62) cohort. This corresponds to a 112.5 per cent increase from the earliest to the most recent cohort. In other words, the gender gap that had already existed among the earliest cohort widened due to the larger increase over time of the proportion of women than men who ever provided care. Furthermore, a major part of the widening of the gap occurred past age 40 .

The shift of the curves towards the left indicates that the onset of a first care episode occurs at a younger age in later than in earlier cohorts. This finding is surprising, considering the increase in life expectancy over the past few decades. Indeed, one might have expected that care needs would come later in the lives of individuals and that their caregivers would be correspondingly older. Therefore, the years gained in life expectancy may be disabled years. As well, this could suggest that caregiving is not confined within conjugal and parent-adult child relationships, but may span more than two generations, leading young adults to be providing care to elderly persons.

Table 3 examines this issue by comparing the proportions of respondents who provided care for the first time before age 45 years across cohorts, depending on their relationship with the care recipient. The relative prevalence of the episodes of care to spouses or partners, to parents or parents-in-law, and to other relatives has all declined across cohorts. Part of the decline in the provision of care to a partner may be linked to the better health status of individuals under the age of 45 years. In addition, the greater level of conjugal instability experienced by the two most recent cohorts compared to their predecessors may have limited the possibility to rely on a partner when in need of assistance. Even though the relative prevalence of providing care to parents or parents-in-law has declined over time, it still constitutes the majority of first care episodes occurring early in life. 
Table 3. Respondents aged 45 years and over in 2007 who provided care to their first care recipient before the age of $45(\%)$, according to birth cohort and relationship with the care recipient

\begin{tabular}{lccccr}
\hline & Born prior to 1933 & $1933-42$ & $1943-52$ & $1953-62$ & Total \\
\hline Spouse/partner & 9.8 & 6.5 & 5.8 & 4.8 & 5.7 \\
Parent/parent-in-law & 67.1 & 66.8 & 64.9 & 58.5 & 62.0 \\
Grandparent & 1.2 & 4.4 & 5.6 & 10.1 & 7.4 \\
Other relative & 16.4 & 15.7 & 15.0 & 14.4 & 14.9 \\
Non-relative & 5.4 & 6.6 & 8.7 & 12.3 & 10.0 \\
\hline N (unweighted) & 350 & 552 & 1,178 & 1,775 & 3,855 \\
\hline
\end{tabular}

Note: Significant at $p<0.001$. Some percentages do not add up to 100 due to rounding. The percentages are based on population weight data.

Source: General Social Survey 21.

In contrast, the proportions of respondents who have helped a grandparent or a non-relative have risen significantly over time. The former, which constituted only 1 per cent of all first care episodes starting before age 45 years for the earliest cohort, increased to 10 per cent among the most recent cohort. Similarly, the prevalence of help to non-relatives more than doubled, going from 5 per cent to 12 per cent of all first care episodes reported before age 45 years. The finding regarding the care to grandparents suggests that as life expectancy increases, relationships, including care relationships, can be maintained over a longer period of time across multiple generations of families — a social trend already noted by Bengtson (2001). Friends form the majority of non-relative caregivers. This category has probably increased in relative importance, because friends might in part compensate for the absence of support from partners or other relatives that is associated with the profound changes that families have experienced over the last 40 years.

\section{Discussion}

As already noted above, the provision of unpaid care is a very common experience. Using the 2007 GSS, Fast et al. (2013) estimated the proportion of individuals who had ever provided care at 40 and 52 per cent, respectively, for men and women aged 45 years and older. In this paper, we showed that 39 per cent of Canadians aged 45 years and over have provided care at some point in their lives for a period of at least six months since the age of 15 years. Among women, the proportion is higher with 45 per cent who assisted at least one person since age 15, although not as high as the proportion reported by Fast et al. (2013). As mentioned in the Data and Methods section, our calculations underestimate the proportion of Canadians who ever provided care since we had to exclude all those who had provided care, but who could not provide the start dates of all their care episodes. A large number of cases were excluded because they had provided care to more than one person in the past 12 months, but only the start date of the care episode for the main care recipient was collected by Statistics Canada. We had to exclude those cases because we needed start dates from all care episodes to order them correctly and be able to capture the timing of the first care episode. In addition, we only considered as caregivers individuals who reported providing care at least once for at least six months. A number of respondents had just started providing care in the year of the survey and as such, remained in our sample, but were not considered to have been caregivers at least once for six months or longer. Despite our conservative estimates, we do not expect them to affect the cohort differences observed in Figure 1, since we did not find any significant differences between cohorts in the percentages of cases with missing information on caregiving variables.

The use of life tables clearly showed that the provision of care has increased over time. The proportion of women in the two most recent cohorts who had provided care at least once in their lives by the time they participated in the survey is already higher than the percentages discussed above. These individuals were all under 64 years of age at the time of survey. Those who had not yet provided care over the course of their lives could eventually take on caregiving responsibilities as they continue to age. The deinstitutionalization of the elderly in the public health system may have sustained the trend in first care witnessed across cohorts. Although, the 
Proulx: The provision of unpaid care across cohorts and genders

possibility that caregiving is perceived differently—with later cohorts more likely to report episodes of care than earlier cohorts—clearly cannot be minimized in accounting for the trend observed.

The life table analysis also showed that not only are respondents from more recent birth cohorts more likely to have ever been a caregiver, they also started doing so for the first time at a younger age. This last finding was counter-intuitive given the marked increase in life expectancy over the past century. If care needs occur later in life, we could have expected caregivers, who oftentimes are the adult children of the care recipient, to be older as well. However, living a longer life does not necessarily mean that it will be exempt of illnesses or disabilities. The increase in life expectancy witnessed over the past several decades in the U.S. and in Canada is linked to increased survival with disease (Crimmins 2004; Mandich and Margolis 2014). The health of seniors generally improved in the 1980s and 1990s although they live longer with diseases. In the 1970s, there was an increase in mild disability among the elderly followed by a decrease in the 1980s and 1990s (Crimmins 2004). However, rates of severe disability increased among the U.S. working-age population over these last two decades (Bhattacharya et al. 2005). The latter trend has been associated to the greater prevalence of a number of chronic diseases and of rising disability among chronically ill individuals (Bhattacharya et al. 2005).

Severe disability is still more characteristic of the oldest old than the working-age population. Research using the 2009-10 Canadian Community Health Survey showed that, while severe disability occurs on average around the age of 77 years, moderate disability — the inability to perform some activities because of a limitation in vision, hearing, speech, mobility, dexterity, feelings, cognition or pain—usually appears around age 40 (Decady and Greenberg 2014). Hence, almost a third of all individuals aged 15 years and over who received care in Canada in 2012 were aged 45-64 years old (Sinha and Bleakney 2014). The fact that a greater share of people survive into older ages but are not necessarily healthy during these extra years may have contributed to the increase in the proportions of Canadians who provided care. That a good share of those who need assistance are middle-aged adults, a proportion that might have risen given the increased prevalence of chronic diseases and related disabilities within this population perhaps helps explain the fact that over the last few decades, Canadians have started providing care at ever-younger ages.

Another part of the explanation for the observed trend in the timing of the first care episode lies in the diversification of the relationships of care. While providing assistance to a parent still remains the most common care relationship, even among first episodes starting before age 45, baby boomers were found to be involved to a greater extent in the care of their grandparents than their parent generation was. Undoubtedly, this finding is associated with the increase in life expectancy that makes possible interactions and exchanges across more than two generations within families. Helping an ill or disabled grandparent was almost unheard of in the earlier cohorts, but is becoming an increasingly common phenomenon. The likelihood of starting to provide care for the first time before the age of 45 to a non-relative has also increased across cohorts, while the likelihood of helping a spouse or partner has decreased. This suggests that social support may be sought in friendships when other sources of support, such as the care from a partner, may be lacking. Further research in this area is needed in order to assess the role that non-relatives are likely to play in the future.

Given the trend towards more egalitarian gender norms and the estimates published in studies using GSS data, we were surprised to find that the proportion of women who engaged in caregiving increased more rapidly across cohorts than it did for their male counterparts. Whether this result reflects a stable trend or a difference in how men and women perceive, recall and report episodes of care is unclear, but it challenges our expectations and motivate us to find an explanation. The gap between the proportions of women and men who engage in caregiving is larger when we consider the care provided at any point over the life course since age 15 rather than the care provided in the past 12 months (see Table 1). Our results suggest that the small differences found at every age cumulate to yield larger gaps after several years of observation. The gender gap in the probability of providing care already widens across cohorts by age 40, but it increases even more after that age.

Guberman and her colleagues (2011) suggested that the identity of baby boomers regarding caregiving responsibilities might have been different than their parents' identity. Women constituted the overwhelming majority of their sample and family responsibilities have traditionally been considered part of women's role. Could it be possible that men and women of different birth cohorts see things differently? At the time when gender roles were much more segregated, men who engaged in caregiving might have been very much aware 
that these responsibilities were unusual for men of their time whose lives were primarily defined by paid labour. This may have led them to recall those moments of their lives vividly and to report them once questioned on them, even several years later. On the other hand, women of the earliest cohort could have minimized the care they provided in their lives, as this was just a natural part of their roles of mothers, daughters and sisters. As gender roles became more similar, women may have recognized the care they provided as such. Later cohorts of women and men may thus have reported their episodes of care in a way that is more similar. In a sense, the increasing gender gap in first caregiving revealed by our results does not necessarily mean that genders have become more unequal in the domain of unpaid caregiving. Additional research would be needed to examine more closely how gender differences evolve across the life course and over historical time in terms of the provision and meaning of unpaid care. Interviews with men and women from the generations preceding the Baby Boom could shed light on this issue.

All things considered, our analysis suggests that the provision of care increased over time and that social support will continue to be an important part of the lives of Canadians in decades to come. It should thus remain an important area of study. The decreasing age at the onset of care raises a number of questions regarding the consequences that these responsibilities might have on the life course of individuals. A large proportion of the later cohorts had already provided care to at least one person before reaching the age of 45 years. Compared to earlier cohorts, these individuals have also delayed childbearing. This suggests that unpaid caregivers are increasingly likely to juggle multiple responsibilities in the future, raising young children while being employed. More refined studies of the repercussions that the provision of care exerts on individuals' employment, conjugal and family relations and health are needed in order to develop policies that meet the needs of these individuals. In addition to providing care at earlier ages, many will be caregivers more than once over the course of their lives and may need different kinds of support at different life stages.

The 2007 GSS is a useful data set to study caregiving over the life course, but it is not without limitations. Various pieces of information about the care provided by respondents were not collected retrospectively for the episodes of care that occurred since the age of 15. For instance, the survey did not contain information about the tasks accomplished, their frequency, and the number of hours per week taken up by caregiving responsibilities. Furthermore, a large number of cases had to be excluded, because information was not collected about the provision of care in the twelve months prior to the survey to individuals other than the main care recipient. Without the start dates of all episodes, we could not assume that the care provided to the main care recipient was the first episode to occur in the life of these respondents; thus, they could not be included in studying the timing of the first care episode. Collecting more information on all the episodes that occurred in the twelve months preceding the survey could be an interesting supplement to add to future collections of the GSS on social support and should not be too difficult to do as it used to be done in 1996 and 2002. At the least, Statistics Canada could collect information on the relationship with the care recipient as well as the start and end dates of each episode, as it does in the care history section. In addition, gathering information on whether other people provide assistance to the care recipient, or support the caregiver by taking on some of his or her tasks, could help us to understand whether the involvement of grandchildren or of friends compensates for or complements the care that would otherwise be provided by other family members.

\section{Acknowledgments}

Support for this research was provided by the Fonds de recherche du Québec - Société et culture (FRQSC), the Social Sciences and Humanities Research Council (SSHRC) and the McGill Canada Research Chair on Social Statistics and Family Change. The analysis presented in this paper was conducted at the Quebec Interuniversity Centre for Social Statistics (QICSS), which is part of the Canadian Research Data Centre Network (CRDCN). The services and activities provided by the QICSS are made possible by financial or in-kind support from SSHRC, the Canadian Institutes of Health Research (CIHR), the Canada Foundation for Innovation (CFI), Statistics Canada, FRQSC and the Québec universities. The views expressed in this paper are those of the author, and not necessarily those of the CRDCN or its partners. I would like to thank Céline Le Bourdais for her continued support and Roderic Beaujot for his helpful comments. 


\section{References}

Bengtson, V.L. 2001. Beyond the nuclear family: The increasing importance of multigenerational bonds. Journal of Marriage and Family 63(1):1-16.

Bhattacharya, J., K. Choudhry, and D. Lakdawalla. 2005. Chronic disease and trends in severe disability in working age populations. Trends Working Paper Series (05-4):1-30.

Cranswick, K. 1997. Canada's caregivers. Canadian Social Trends 47:2-6.

Cranswick, K., and D. Dosman. 2008. Eldercare: What we know today. Canadian Social Trends 86:48-56.

Crimmins, E.M. 2004. Trends in the health of the elderly. Annual Review of Public Health 25:79-98.

Decady, Y., and L. Greenberg. 2014. Ninety Years of Change in Life Expectancy. Health at a Glance (Cat. No. 82624-X). Ottawa: Statistics Canada.

Elder, G.H. 1998. The life course as developmental theory. Child Development 69(1):1-12.

Engelhardt, H., and A. Prskawetz. 2004. On the changing correlation between fertility and female employment over space and time. European Journal of Population 20(1):35-62.

Evandrou, M., and K. Glaser. 2002. Changing economic and social roles: The experience of four cohorts of midlife individuals in Britain, 1985-2000. Population Trends 110:19-30.

Fast, J., and N. Keating. 2001. Informal Caregivers in Canada: A Snapshot. Research on Aging, Policies and Practice Series (RAPP). Edmonton, AB: University of Alberta.

Fast, J., K. Duncan, C. Dunlop, J. Eales, N. Keating, D. Lero, and S. Yoshino. 2011. Gender Differences in Family/ Friend Caregiving in Canada.http://sociology.uwo.ca/cluster/en/-PolicyBriefs.html (retrieved 6 September 2013).

Fast, J., N. Keating, L. Derksen, and P. Otfinowski. 2004. Characteristics of family/friend care networks of frail seniors. Canadian Journal on Aging 23(1):5-19.

Fast, J., N. Keating, D. Lero, J. Eales, and K. Duncan. 2013. The Economic Costs of Care to Family/Friend Caregivers: A Synthesis of Findings. Research on Aging, Policies and Practice Series (RAPP). Edmonton, AB: University of Alberta.

Foundation (Foundation for Accountability and The Robert Wood Johnson Foundation). 2003. A Portrait of Informal Caregivers in America, 2001. Portland: Foundation for Accountability.

Fruhauf, C.A., S.E. Jarrott, and K.R. Allen. 2006. Grandchildren's perceptions of caring for grandparents. Journal of Family Issues 27(7):887-911.

Guberman, N., J-P. Lavoie, and I. Olazabal. 2011. Baby-boomers and the 'denaturalisation' of care-giving in Quebec. Ageing and Society 31(7):1141.

Henz, U. 2004. The effects of informal care on paid-work participation in Great Britain: A lifecourse perspective. Ageing and Society 24(6):851-80.

Himes, C.L., and E.B. Reidy. 2000. The role of friends in caregiving. Research on Aging 22(4):315-36.

Hochschild, A., and A. Machung. 1997. The Second Shift. New York: Avon Books.

Keefe, J., P. Fancey, and S. White. 2005. Consultation on Financial Compensation Initiatives for Family Caregivers of Dependent Adults: Final Report. Halifax: Maritime Data Centre for Aging Research and Policy Analysis.

Lavoie, J-P. 2012. Entre État, famille, tiers secteur et marché: Les politiques québécoises à l'égard des personnes âgées ayant des incapacités, in Le vieillissement de la population et les politiques publiques: enjeux d'ici et d'ailleurs, edited by P. Marier. Québec: Les Presses de l’Université Laval, p. 129-51. 
Mandich, S., and R. Margolis. 2014. Changes in disability-free life expectancy in Canada between 1994 and 2007. Canadian Studies in Population 41(1-2):192-208.

Marshall, K. 2006. Converging gender roles. Perpectives on Labour and Income 7(7):5-17.

Matthews, S.H. 2002. Brothers and parent care: An explanation for sons' underrepresentation, in Men as Caregivers: Theory, Research, and Service Implications, edited by B.J. Kramer and E.H. Thompson. New York: Springer, p. 234-49.

Ménard, F-P., and C. Le Bourdais. 2012. Diversification des trajectoires familiales des Canadiens âgés de demain et conséquences prévisibles sur le réseau de soutien. Cahiers québécois de démographie 41(1):131-61.

Protecteur (Le Protecteur du citoyen). 2012. Chez soi: Toujours le premier choix? L'accessibilité aux services de soutien à domicile pour les personnes présentant une incapacité significative et persistante. Québec: Le Protecteur du citoyen.

Ravanera, Z., R. Beaujot, and J. Liu. 2009. Models of earning and caring: Determinants of the division of work. Canadian Review of Sociology 46(4):319-37.

Robison, J., P. Moen, and D. Dempster-McClain. 1995. Women's caregiving: Changing profiles and pathways. The Journals of Gerontology Series B. Psychological Sciences and Social Sciences 50(6):S362-73.

Szinovacz, M.E. 2008. Children in caregiving families, in Caregiving Contexts: Cultural, Familial, and Societal Implications, edited by M.E. Szinovacz and A. Davey. New York: Springer, p. 161-91.

Sinha, M. 2013. Portrait of Caregivers, 2012. Spotlight on Canadians: Results from the General Social Survey (Cat. No. 89-652-X-001). Ottawa: Statistics Canada.

Sinha, M., and Bleakney, A. 2014. Receiving Care at Home. Spotlight on Canadians: Results from the General Social Survey (Cat. No. 89-652-X-002). Ottawa: Statistics Canada.

Statistics Canada. 2010. Population projections for Canada, provinces, and territories 2009 to 2036 (Cat. No. 91 520-X). Ottawa: Statistics Canada.

2013. General Social Survey: An Overview, 2013 (Cat. No. 89F0115X). Ottawa: Statistics Canada. . 2014a. Table 051-0001: Population by sex and age group, CANSIM (database). http://-www.statcan.gc.ca/ tables-tableaux/sum-som/101/cst01/demo10a-eng.htm (retrieved 13 October 2014).

- 2014b. Table 282-0002: Labour force survey estimates (LFS), by sex and detailed age group, annual (persons unless otherwise noted), CANSIM (database). http://www5.statcan.-gc.ca/cansim/ (retrieved 22 September 2014). 